\title{
The Observation of Natural Analogies and Their Use in Design
}

\author{
A. DARABOS \\ Budapest University of Technology and Economics , Faculty of Mechanical Engineering, Department of of \\ Machine and Product Design, darabos.anita@gt3.bme.hu
}

Abstract. According to, Thomas Heatherwick, who was an English architecture, 'The biggest object is a building'. [1] Nature has phenomenal problem solving skills - 'Nature knows it better'. It has an impact on us and on our subconscious.

\section{Introduction}

We can turn to nature to find the perfect solutions to our design-problems. We can take its beauty as a sample. Moreover, we can make our objects more attractive by nature. In this paper we present six methods for the usage of natural analogy.

\section{The unconscious use of nature is inherited from generation to generation}

We could observe inherited material knowledge and flow in nature. These are important and are the part of the process of survival. Furthermore, they also connect to the protection of the offspring.

\subsection{Clay nests and clay huts}

Mud dauper makes the nest out of clay. It builds it for 3 days. The nest is cone-shaped. Mud dauper carries mud in piles and the knots will be smoothed by them. While it carries the other portion, the previous mud will be hard enough to build another layer. It fills the construction with truncated spiders and put the larva beside the spiders then walls the entrance. The huts of Cameroon tribes are still there in Africa. They make the frames out of branches and they plaster it with clay. The bore diameter inside is between 3-4 meters.

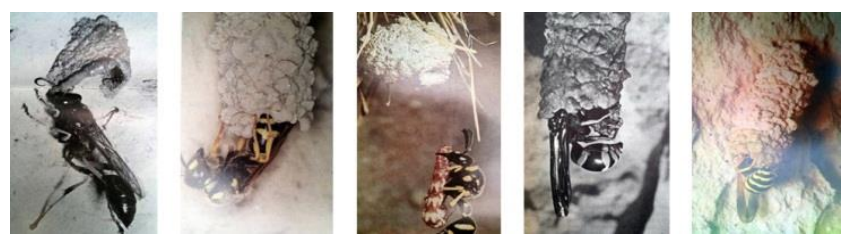

Figure 1. Parts of mud dauper's nest construction 


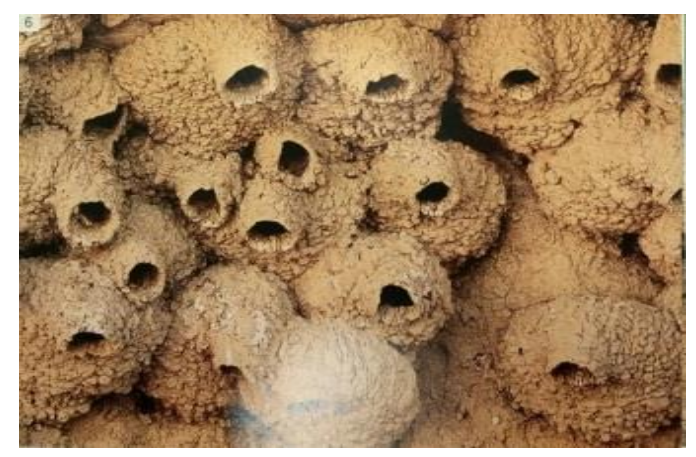

Figure 2. Wasp's nest

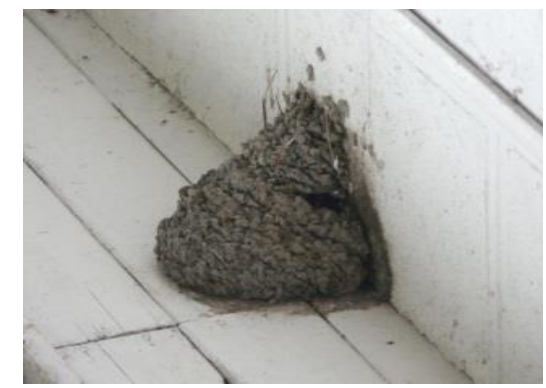

Figure 3. Swallow nest

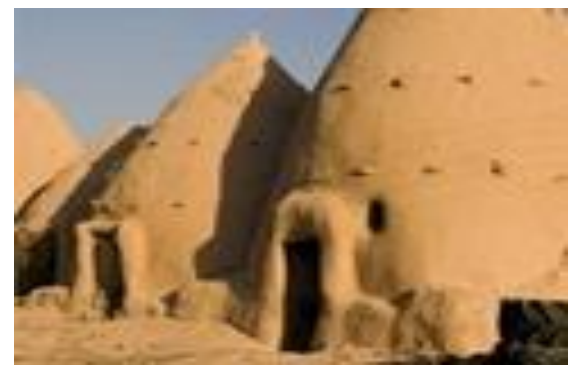

Figure 4. African clay hut

The 3. figure shows the swallow nest, it was bottom-upwards to show the formal similarity between them. In the case of the three different creatures, the knowledge of the building material and the usage are the same. The carriages are different because of the size of the creatures and their physique. What is more, it can alter the construction too. They use different ways of carriages. The swallow carries in its beak, the wasp takes it in its mouth and humans carry the clay in their hands to build a house. But their constructions show similarities.

\section{Learnt process: gives the solution to a problem.}

I have found an example at ancient Egypt. The maps of the Egyptian crypts and wood-beetle's (Anobium punctatum) nutritional holes show similarity. It is interesting that it is like our tomb. On the other hand, ancient Egyptians believed that this is a beginning of a new life, not the end of it. In case of the wood-beetle, they live in the furrow and they are the cradles of the offspring. In my opinion, builders used them as a sample and they used it at the channels also. And there was not only the tracing significant but the order of each tunnel because of the carriage of the material.
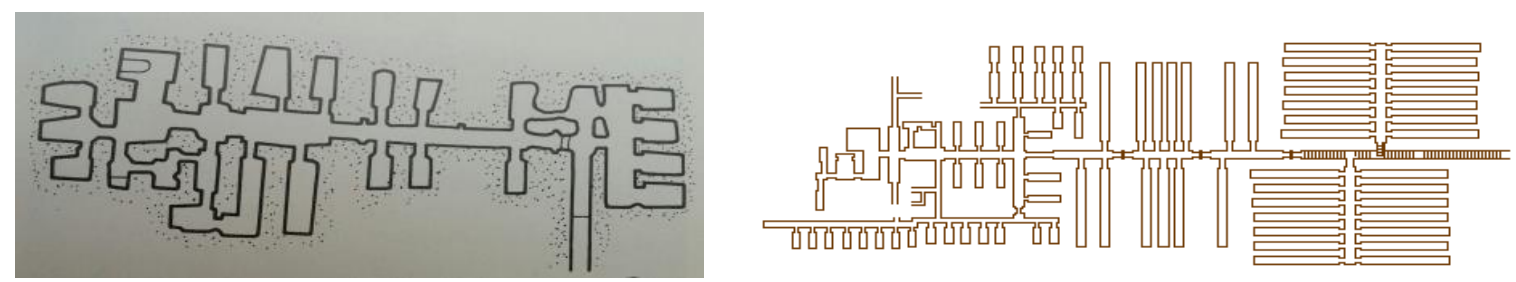

Figure 5. Saqqara 3080 numbered tomb 1-2. din., A.D. 3100 - 2650. 

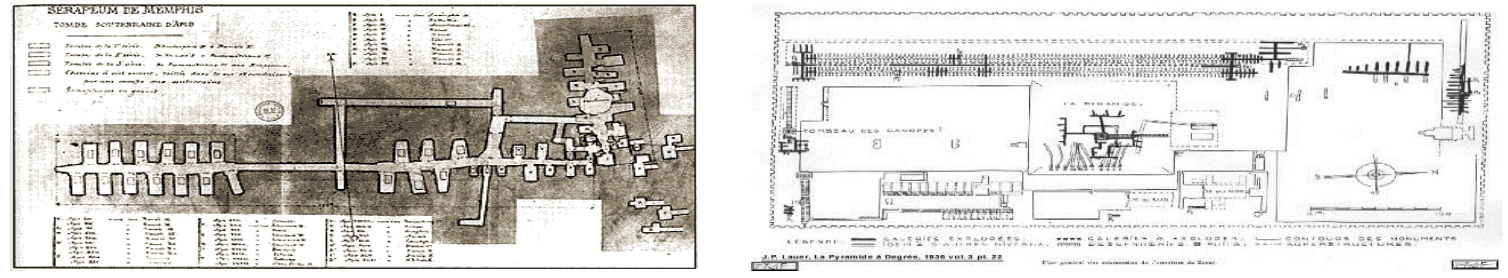

Figure 6. Drawings of Memphis' and Djoser's burial chamber
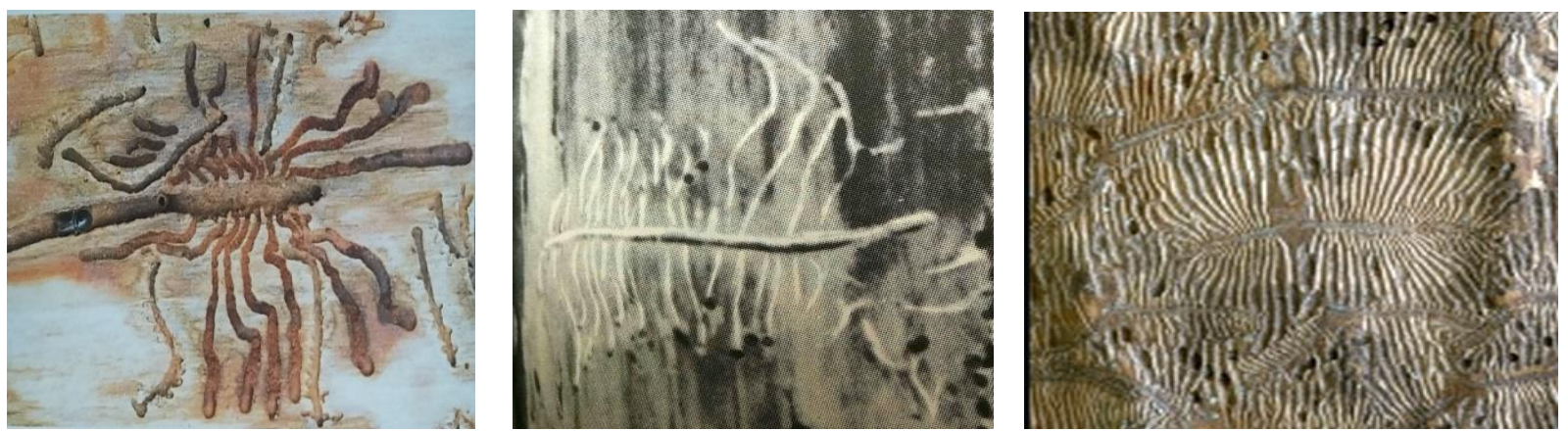

Figure 7. Wood-beetle chewed wood, nourishment and building

Wood-beetle chewed wood, nourishment wrecking and construction. Every wood-beetle has its own style in building and gnaw. It will find another route when there is a hurdle in its path. Some woodbeetle species (Scolytus scolytus F. and Sc. multistriatus Marsh.) make the main lines in parallel. Contrary, some other wood-beetles (Sc. intricatus Ratz.) make it in a horizontal way.

\section{The reflection of the natural beauty in the designer's mind}

The complexity of the shape and colours are inevitable in the case of the product. The design determines marketability. But this depends on harmony. Our opinions depend on strong, subjective elements and the decision making will happen in our unconscious. We were born with the harmony of nature and we still live in harmony with nature against our social environment. We can see the beauty of something when it suggests the phenomenon of nature. Designers should pay attention to the phenomenon of nature and we should also look for the colours, forms and combinations to create a new style. People like the patterns of nature more and the designer could be more successful. This determines designer's style.

For instance I would like to mention the works and the prizes of Zaha Hadid. She was born in Iraq. She was an architect and she lived in the United Kingdom. She was the first woman to receive the Pritzker Prize. She also received the Sterling Prize for MAXXI Museum in Rome, in 2010. She was one of the most famous representatives of Biomorphic architecture. She created her own style. I had discovered it in how she represents ice in architecture.

The Franz Josef glacier in the South Alps and glacier rifts in the southern islands of New Zealand shows them. There will be rifts in steep valleys and they will expand. The rifts are only 30 meter deep. The ice under 30 meter do not break because it will be malleable under the pressure of the layers of ice.

The figures 7. and 8. presents the glaciers and the constructions of Zaha Hadid in some pictures. 


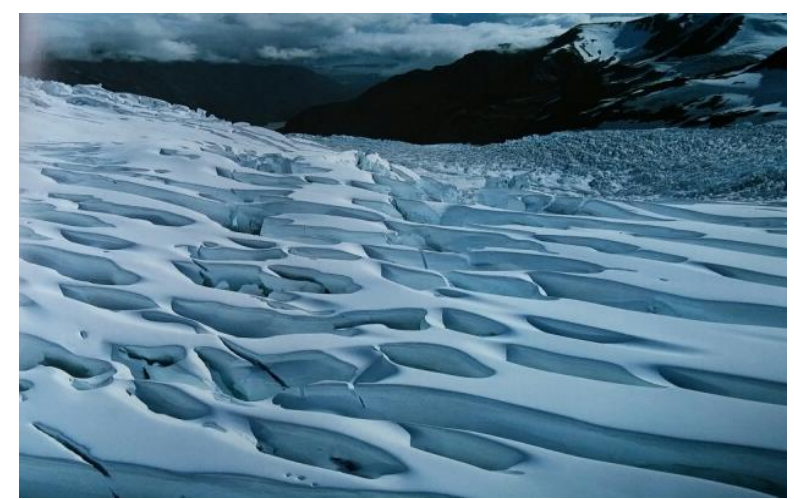

Figure 7. Franz Josef glacier in the South Alps and the southern islands of New Zealand
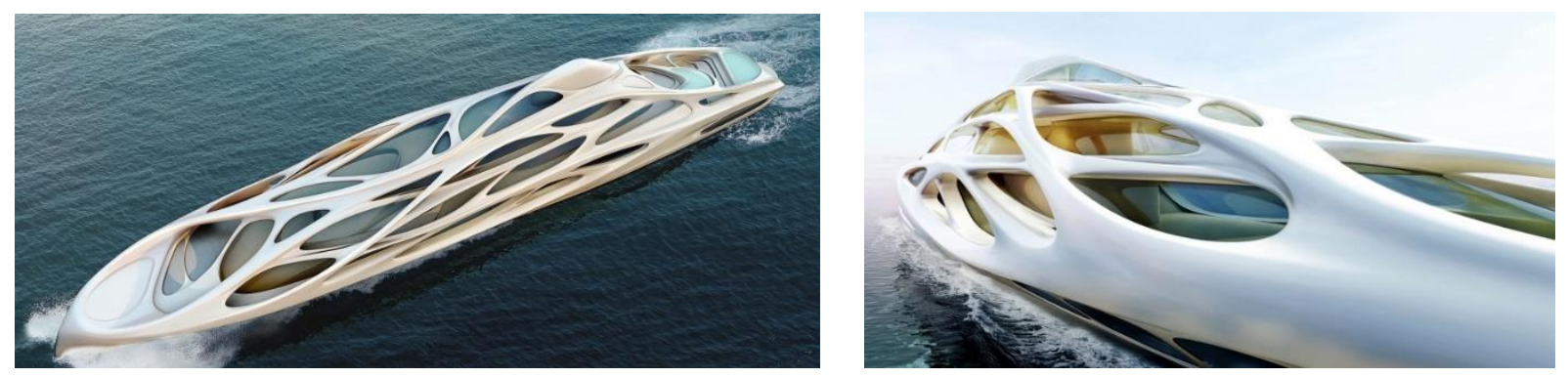

Figure 8. The design of Zaha Hadid's super yacht

\section{4. „Nature works for us”}

This is one of the most extreme ways of natural analogy. This is a special case when humans observe nature and it use the progress of nature. Observation and adaptation are like domestic animals. A creature creates in human's world with new material. In this case, we could see a utilized analogy and natural subject.

Here is the experiment of a French artist and the artistic structures in 2007. He has spent two years with the experiment of caddish-fly's (Trichoptera) artificial living space and to encourage the construction with his commodity. It constructs only in crystal clear water and from natural materials exclusively. It creates larvae to protect its vulnerable body parts. Artificial environment means gold and other aquamarines. The artist exhibits the golden constructions made by caddish-fly in a French jewellery auction. Here you can see how caddish-fly builds from gold and pearl.
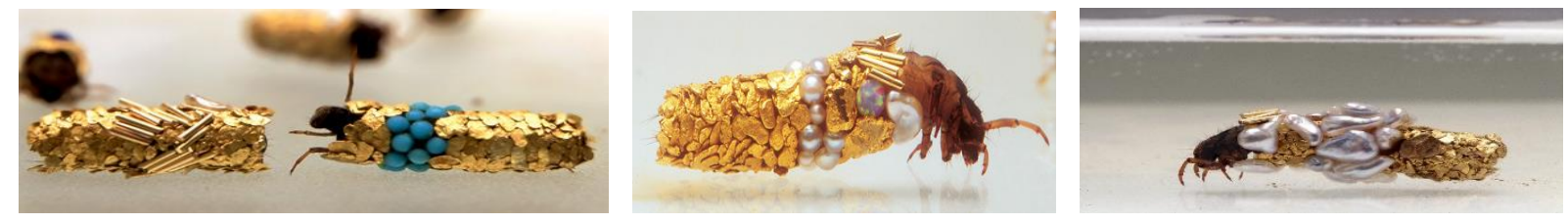

Figure 9. Larvae of caddish-fly, its construction and construction influenced by humans 

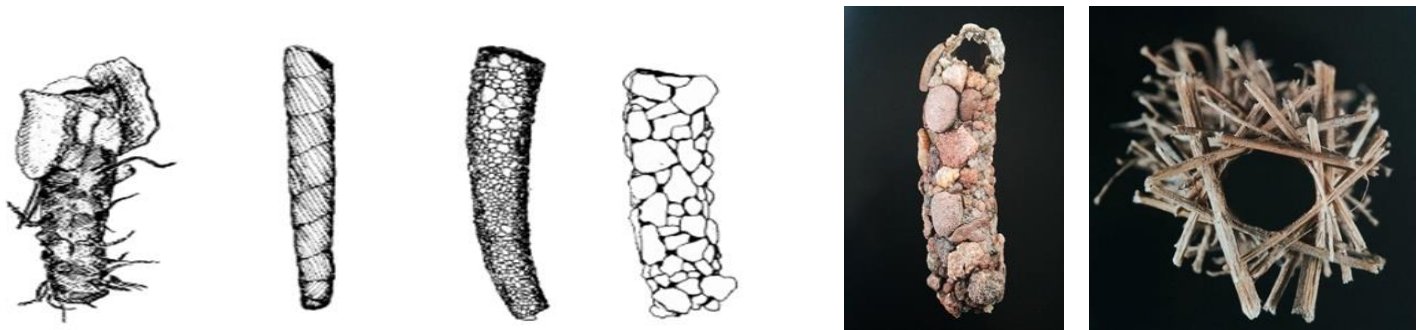

Figure 10. Caddish-fly use the original materials in construction

\section{Pearls - Cultured Pearls}

True pearls are biogenic semi-precious stones made from concentric shells, which are selected by some molluscs to protect themselves against injuries or foreign matter in their bodies. To make artificially created pearls, insert plastic pearls into the living shellfish. Mokichi Mikimoto continued his experiments in Ago Bay in 1858, discovering that foreign matter could be bred in the shell. In 1899, at Tokio, Ginza, he opened his first store of pearls. The miracles of nature, if we are well-observed and analyzed, are made to be replicated or used in production.
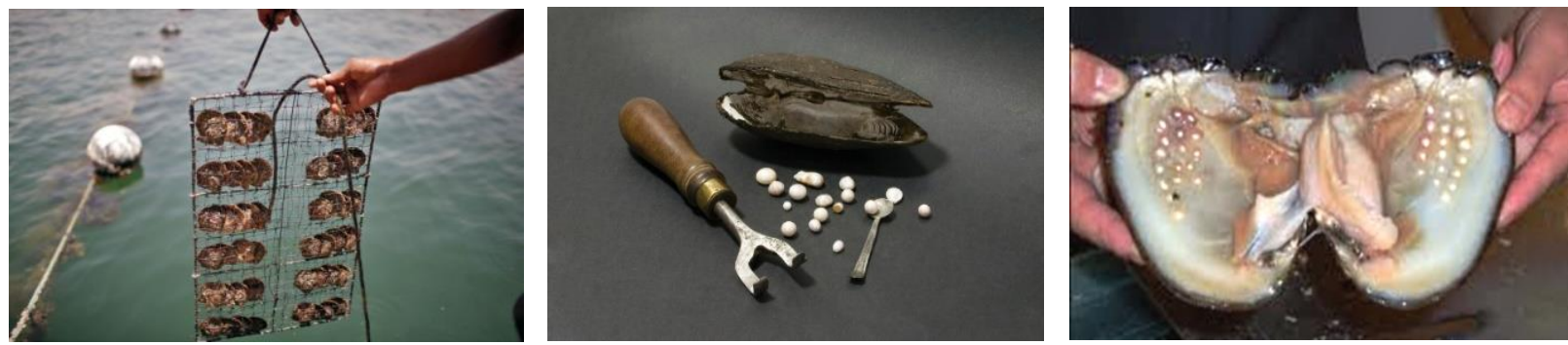

Figure 11. Phases of cultured pearls making

\section{Silkworm silk}

The most beautiful and finest natural styles from which you can produce precious noble fabrics. Taking advantage of the nature, we are knocking down an animal's defensive puppet to cover our own body with this woven cloth. According to the legend, Empress Emperor Hsi Ling Si is a Chinese emperor. He lived around 2640, accidentally dropping a silk cube into his hot tea, which softened the heat and made a long, fine yarn. Even in ancient times, Roman patriots and Japanese emperors were wearing silk dresses.

From the 2nd century B.C., silk was transported by traders on silkworms. In the Eastern Roman Empire Emperor Justinian (527-565) spread the silkworms cultivation, after 552, in two redeeming monk bamboo shoots, smuggled some of the silkworms into Byzantium. In Hungary János Passardi Péter was in 1680 to breed silkworms. The most beautiful and finest natural styles from which you can produce precious noble fabrics. 

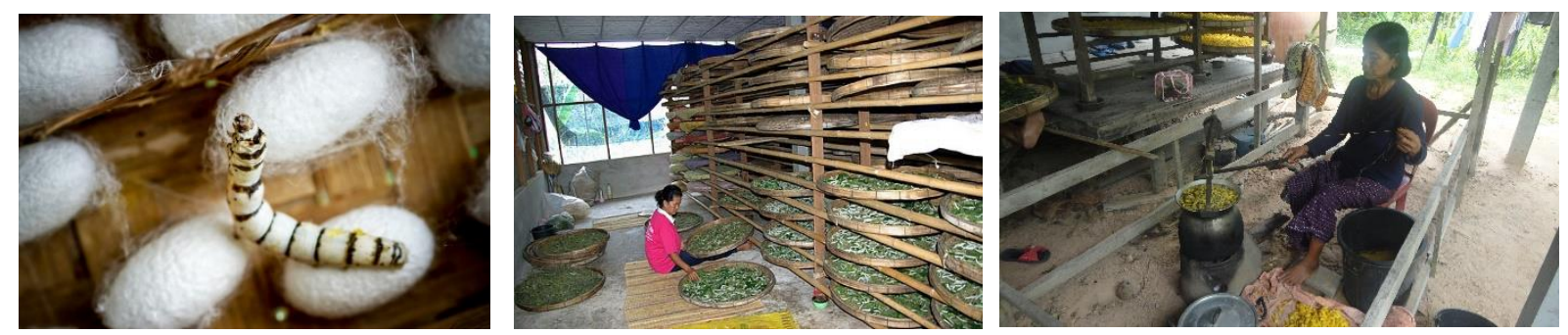

Figure 12. Silkworm, feeding, cooking rattle

Today there is mechanized production. The machines produce as many silk threads per hour as a small manufactory per day. The increased demand demanded mechanization. What a perfect material this small animal has created, even for large-scale machine manufacturing.
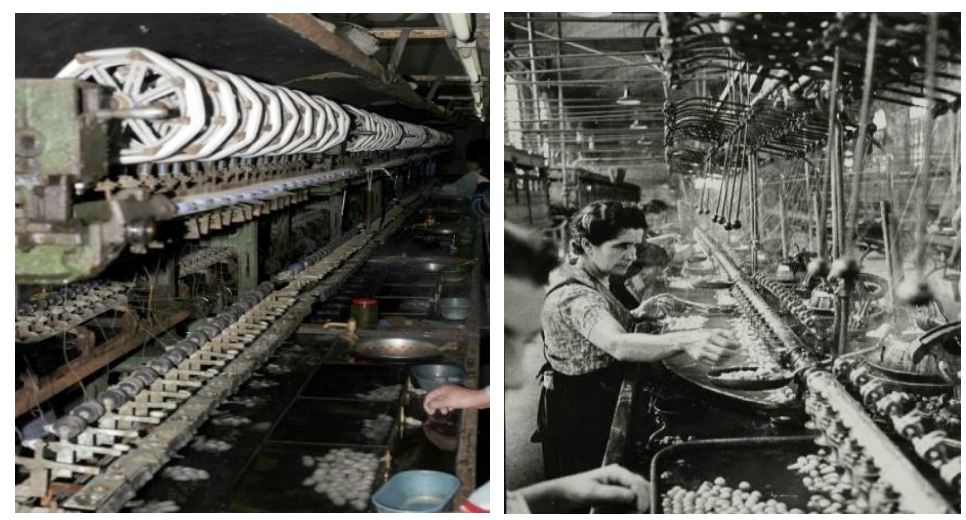

Figure 13. processing mechanized

\section{Conclusion}

This collection of six methods is really interesting for product designers. I have made a system out of the experiments of the analogogy and their usage itself. There are more methods than I have mentioned in this paper. But the main goal of this study is to learn and practice the knowledge and the information that naturally aggregates over millions of years and give us. We should only notice it.

\section{Thanksgiving}

The research reported in this paper was supported by the Higher Education Excellence Program of the Ministry of Human Capacities in the frame of Artificial intelligence research area of Budapest University of Technology and Economics (BME FIKP-MI).

\section{References}

[1] T. Heatherwick, M. Rowe: Making. Thames \& Hudson, 328. 